\title{
Effectiveness of Family-Based Behavioral Treatment Based on Medication Behavior Barkley Compared with Drug Therapy in Reducing the Symptoms of Children with Attention Deficit Disorder-Hyperactivity
}

\author{
Narges Dolatyari, Seyyed Hossein Seid \\ Department of Clinical Psychology, College of Psychology, Science and Research Branch, Islamic Azad \\ University, Alborz, Iran \\ Email: ${ }^{\text {hosseinseid@yahoo.com }}$
}

Received 12 December 2014; accepted 8 April 2015; published 20 April 2015

Copyright (C) 2015 by authors and Scientific Research Publishing Inc.

This work is licensed under the Creative Commons Attribution International License (CC BY).

http://creativecommons.org/licenses/by/4.0/

(c) (i) Open Access

\begin{abstract}
Children with attention deficit and hyper activity disorder have various problems such as low academic performance, social and communication problems, anxiety, depression, aggression, conduct disorder and delinquency, and also when they become adults, they have problems in social relationships that these problems can increase or decrease in dealing with family. Hence, this study was performed in order to examine the impact of family-based behavioral treatment compared with Barkley behavior therapy in reducing symptoms of children with attention deficit disorder-ADHD. To meet the aim, 20 of children with age range of 7 to 12 years old with attention deficit disorder-hyperactivity were selected in both experimental and control groups, and exposed to the treatment of behavioral family therapy groups and changes in behavior Barkley. Before and after the treatment, they were evaluated according to the scale of the Conner's Parent Rating Scale-Revised Short Form (CPRS-R: S). Results of multivariate analysis of covariance indicated that there were significant differences between the experimental group who had received family-based behavioral treatments based on changes in behavior Barkley and a control group who had received drug treatment in variables, including conduct problems, learning problems, psychosomatic symptoms, and signs of impulsive hyperactivity, anxiety and hyperactivity $(p<0.01)$. These results could be guidance for counsel or sand therapists for children with attention deficit disorder-ADHD.
\end{abstract}

"Corresponding author.

How to cite this paper: Dolatyari, N. and Seid, S.H. (2015) Effectiveness of Family-Based Behavioral Treatment Based on Medication Behavior Barkley Compared with Drug Therapy in Reducing the Symptoms of Children with Attention Deficit Disorder-Hyperactivity. Health, 7, 481-486. http://dx.doi.org/10.4236/health.2015.74057 


\section{Keywords}

\section{Family Behavioral Treatment Based on Barkley Behavior, Medication, Clinical Symptoms, Impaired Attention Deficit-Hyperactivity}

\section{Introduction}

Study and research on children and adolescents with emotional and behavioral disorders are one of the main areas, leading and penetrating in pathological and clinical psychology, and among a variety of childhood disorders, attention deficit disorder-hyperactivity is the most common neurological-behavior disorder that is detected in the course of childhood (before age 7). Among the most common behavioral problems in children with attention deficit disorder, hyperactivity disorder has the highest number of scientific studies, so that about 100 scientific papers are published about it each year [1].

Attention deficit hyperactive disorder is the most common behavioral disorders of childhood [2], which has been reported in 7\% of children and $3 \%$ of adults [3]. In addition to the main problems of children with this disorder, they suffer from attention, impulsivity and hyperactivity in various fields of social, academic, behavioral, cognitive and emotional areas [2]. People with attention deficit disorder/hyperactivity may show unusual characteristics such as impulsiveness, restlessness or hyperactivity, inability to focus, or a combination of these behaviors. Children with attention deficit and hyperactivity disorder are dealing with various problems such as low academic performance, social and communication problems, anxiety, depression, aggression, conduct disorder, and delinquency, and in adulthood they will have problems in social relationships, career and marriage [4]-[6]. Several cognitive and behavioral disorders such as attention deficit is order are observed in children with attention deficit and hyperactivity [7] [8]. Such cognitive and behavioral disturbances may cause difficulties in academic achievement and daily activities at home and in social situations [9] [10]. While researchers study such behavior, they have begun to consider beyond features and conceptualization of disability as severe self-management, impulse control, and activity level. Research on attention deficit disorder-hyperactivity reflects reading on concepts such as executive function ability, monitoring and managing individual behavior, impulse control, attention, and thinking about the consequences of your actions [11] [12].

Although several treatments for attention deficit disorder/hyperactivity have been developed, few of them have enough or too preliminary empirical support. These therapies include medication, parent training/consultation with parents, cognitive-behavioral therapy and neuro feedback and anastopoulos therapy [13].

These treatments decrease the symptoms of attention deficit/hyperactivity and improve emotional and behavioral problems in children with ADHD. Therefore, the main objective of the proposed study is to compare the efficacy of behavioral therapy based on Barkley family behavior change and medication in reducing symptoms in children with attention deficit disorder-ADHD.

\section{Method}

The study was a quasi-experimental research, so 20 of children 7 to 12 years old in Karaj who suffered from attention deficit disorder-ADHD were selected. These patients referred to two clinical psychologies and by using two sampling methods were selected, so 10 children put as the experimental group and 10 children were as a control group.

\section{Research Design}

The design of present study is in this way that first two clinical psychology where children with attention deficit disorder-hyperactivity referred there have been identified and among them the 10 children with attention deficit disorder - hyperactivity were selected after matching the input criteria such as (a primary diagnosis of attention deficit disorder and dominant-ADHD, aged between 5 and 7 years, having the mother alive) and the experimental group received behavioral therapy on behavior change Barkly and others in a control group who received medical treatment. Before treatment, each group was given pre-test and after completion of treatment, they were given a post-test and collected data were analyzed by using SPSS software. 


\section{Instruments}

The methodology of present study is field method and instruments are attention deficit disorder diagnostic questionnaire, the short form and Revised Rating Scale of the Conners' Parent.

1) Attention Deficit Disorder Diagnostic Questionnaire: The purpose of this questionnaire is isolation and diagnosis of attention deficit disorder children with other children. The questionnaire has been prepared based on Attention deficit disorder diagnostic criteria and Statistical Manual of Mental Disorders Fourth Edition by [14] and included nine questions with multiple-choice Likert scale (never-sometimes-often-always). [14] determined reliability of this questionnaire 96/0 by Cronbach's alpha. The maximum score for this test is 27 and minimum score of zero and Score above 18 is considered as the attention deficit disorder.

2) Short for Man Revised Conner's Parent Rating Scale (CPRS-R: S): Conner questionnaire has two forms of parents and teachers. Parents' scale has 48 questions that evaluate 5 groups of ADHD children, including learning disabilities, conduct disorders, psychosomatic problems and hyperactivity and impulsivity and anxiety movement. 10 questions are for ADHD aged 12 - 7 years which is scored from zero to three (no time (0), low (1), relatively high (2), and high (3)). The average $5 / 1$ and the higher imply the kinetic hyper activity disorder. By this measure, 74 percent of children are identified and in teachers' form, children between 6 to 13 years are evaluated with 28 questions, and 7 questions have been assigned for kinetic hyper activity disorder. To obtain an average score of 1.5 or higher on attention deficit and hyperactivity disorder implies, if the child is found to be higher than 34 indicate disorder. The higher the rating, the greater will be the child's disorder and vice versa.

\section{Result and Discussion}

In order to analyze research data, multiple covariances were used. Therefore, the experimental group and the control variables as in dependent variables, size of the different components of the test, conduct problems, Learning problems, psychosomatic symptoms, signs, impulsive hyperactivity, anxiety, hyperactivity as indicators covariate variables and the sizes of the different components of the posttest in conduct problems, Learning problems, psychosomatic symptoms, signs, impulsive hyperactivity, anxiety, hyperactivity indices as dependent variables were entered into the analysis process.

Kroite Bartlett's test was used to examine the association between measures of the dependent variable. The results indicated that this testis significant $(\mathrm{p}<0.01)$ this shows that there is sufficient correlation between the size-dependent analyses for multiple covariances. Also, the results of the test of equality of error variance Levees is not significant. This matter implies that the error variance between the independent variables is the same for all levels. In order to answer the question of the current study, the researchers were selected among four statistics (Pillai's Trace, Wilks' Lambda, Hoteling's Trace, and Roy's Largest Root) in order to measure F value.

Wilks Lambda statistic indicates that $F=12.90, p<0.001$, so, it can be possible to reject the similarity hypothesis based on independent variables for both groups. And it can be concluded that there was a significant difference between the clinical symptoms of hyperactive children who received behavioral the rap and familybased behavior modification Barkley hyper active children who have received treatment. Now, in order to understand which of the variables are different, the results of analysis of variance between groups have been used.

As shown in Table 1, there are significant differences between the experimental group who had received behavioral family treatments based on Barkley's behavior and a control group who had received drug treatment variables in conduct problems, learning problems, psychosomatic symptoms, signs, impulsive hyperactivity, anxiety, and hyperactivity $(\mathrm{p}<0.01)$.

Thus, behavioral family therapy based on Barkley's behavior causes that the experimental group had a better performance on conduct problems, learning problems, psychosomatic symptoms, signs, impulsive hyperactivity, anxiety, and hyperactivity index than the control group. In Table 2, clearly shows lower the mean of the experimental group in the post test different components of behavior problems, learning problems, psychosomatic symptoms, signs, impulsive hyper activity, anxiety, and hyperactivity.

Attention deficit disorder-ADHD is one of the most common chronic disorders which approximately seven percent of children and teens are suffering from it. This disorder causes considerable deficit in the child's daily life and in addition to its their main symptoms which are include stirring, impulsivity, and attention deficit, causes some deficiencies in the areas of academic, interpersonal and social which often continues to adult hood. Research shows that if this is not detected early and appropriate treatment, this disorder provides a lot of cost for the family members, school staff and the community. 
Table 1. ANOVA results for the effect of group and interaction effect of the components of clinical problems.

\begin{tabular}{ccccccc}
\hline Sig & F & $\begin{array}{c}\text { Average } \\
\text { Square }\end{array}$ & $\begin{array}{c}\text { Degree of } \\
\text { Freedom }\end{array}$ & $\begin{array}{c}\text { Total } \\
\text { Square }\end{array}$ & Dependent Variable & $\begin{array}{c}\text { Source of } \\
\text { Variation }\end{array}$ \\
\hline 0.001 & 8.2 & 378.66 & 1 & 378.66 & Conduct Problems & Learning Problem \\
0.001 & 12.11 & 98.88 & 1 & 98.88 & Groups \\
0.002 & 10.54 & 99.22 & 1 & 99.22 & Psychosomatic Symptoms & Impulsive Symptoms More Active \\
0.001 & 13.22 & 987.67 & 1 & 987.67 & Symptoms of Anxiety & Indicators of Hyperactivity \\
0.007 & 9.34 & 76.31 & 1 & 76.31 & 768.07 & \\
\hline
\end{tabular}

Table 2. Descriptive information about experimental and control groups at pre-test and post-test of clinical symptoms.

\begin{tabular}{|c|c|c|c|c|c|}
\hline \multicolumn{2}{|c|}{ Posttest } & \multicolumn{2}{|c|}{ Pretest } & \multirow{2}{*}{ Components } & \multirow{2}{*}{ Groups } \\
\hline Standard Deviation & Mean & Standard Deviation & Mean & & \\
\hline 5.44 & 53.05 & 6.12 & 61.05 & Conduct Problems & \\
\hline 2.45 & 57.05 & 2.43 & 68.95 & Learning Difficulties & \\
\hline 2.13 & 44.5 & 2.89 & 69.25 & Psychosomatic Symptoms. & Behavioral \\
\hline 5.37 & 49.85 & 7.05 & 67.45 & Impulsive Symptoms of ADHD & Therapy Barkley \\
\hline 3.47 & 47.81 & 3.22 & 64.19 & Symptoms of Anxiety & \\
\hline 5.05 & 54.55 & 8.46 & 62.28 & Indicators of Hyperactivity & \\
\hline 2.76 & 62.05 & 5.19 & 69.05 & Conduct Problems & \\
\hline 2.41 & 58.95 & 3.47 & 62.95 & Learning Difficulties & \\
\hline 2.18 & 52.25 & 4.77 & 62.25 & Psychosomatic Symptoms. & \\
\hline 3.54 & 49.45 & 3.87 & 64.45 & Impulsive Symptoms of ADHD & Drug 1шстару \\
\hline 3.49 & 52.12 & 4.98 & 65.56 & Symptoms of Anxiety & \\
\hline 4.98 & 53.23 & 3.4 & 66.66 & Indicators of Hyperactivity & \\
\hline
\end{tabular}

In Iran, the most common treatment in these children is using intervention of drug while this is not complete and conclusive treatment .However, in some children may cause side effects and it has also been found that the use of medications, causing families with children with attention deficit disorder/hyperactivity don't use other complementary therapies including psychological treatment. Hence, a researcher would like to investigate the effects of family-based behavioral treatment for children with behavior Barkley on clinical symptoms of attention deficit disorder-ADHD in this study.

Results of multivariate analysis of covariance indicated that behavioral family therapy based on Barkley's behavior cause that the experimental group had better performance in conduct problems, learning problems, psychosomatic symptoms, signs, impulsive hyperactivity, anxiety symptoms, and hyperactivity index than control group who had received drug treatment.

The investigation on the interactions of inter family children with ADHD attention deficit/hyperactive, indicating that the families of these children may have a difficulty in relationship with each other [15]. Usually, these children are born in unusual families and they have been reported psychological problems in these families. In studying the interaction between parents and children in families of children with attention deficit disorder/ hyperactivity in Iran has shown that these parents use styles of authoritarian and autocratic more than normal parents of [16].

Parents who have less confidence use more punitive approach and have less warm relationships with their children [17]. Also the study on children the with personality disorder attention deficit /hyperactivity parents in- 
dicated that there is stress imposed relations authority depression, limitations, high failure and low capacity [18] in their relationships. Research shows that most of the damage that can be seen in the relationship between parents and children with attention deficit disorder/hyperactivity is behavioral problems in communication between parents, as well as of children with ADHD.

So, today, according to new research and effective treatment strategies, especially in explaining the etiology of attention deficit disorder/hyperactivity level of parental behavior has been determined that the interaction between parents of children with this disorder, is a very important issue that should not be neglected by researchers and practitioners

So today psychological therapy and skills training, behavior management and stresses that emphasizes on parents and children in the treatment of this disorder is often a priority and is useful [19].

\section{Conclusions}

Hence, due to the mentioned introduction of the importance of family and family engagement in children with attention deficit disorder/hyperactivity disorder and its impact on children's behavior, the results of this research can be justified.

In line with the results of this study, counselors give parents' life skills in the form of poster or presentation to parents so that clinical and behavioral problems can be prevented in children.

\section{Limitations and Implications}

1) Lack of sincere cooperation of parents of children with Attention deficit hyperactivity disorder in the treatment and assessment of the limitations of this study;

2) Lack of cooperation of some parents that this study was conducted, resulting in the interruption of the process have been investigated;

3) The results can be used by psychologists and therapists hyperactivity disorder.

\section{References}

[1] Ryff, C.D. (1985) Adult Personality Development and the Motivation for Personal Growth. In: Kleiber, D. and Maher, M., Eds., Advances in Motivation and Achievement: Motivation and Adulthood, Vol. 4, JAI Press, Greenwich, 55-92.

[2] Boles, D., Adair, L. and Joubert, A. (2009) A Preliminary Study of Lateralized Processing in Attention-Deficit/Hyperactivity Disorder. The Journal of General Psychology, 136, 243-258. http://dx.doi.org/10.3200/GENP.136.3.243-260

[3] Hong, Q., Zhang, M., Pan, X., Gue, M., Li, F., Tong, M., Chen, R., Gue, R. and Chi, X. (2009) Prefrontal Cortex Homer Expression in an Animal Model of Attention-Deficit/Hyperactivity Disorder. Journal of the Neurological Sciences, 287, 205-211. http://dx.doi.org/10.1016/j.jns.2009.07.024

[4] Modestin, J., Matutat, B. and Würmle, O. (2001) Antecedents of Opioid Dependence and Personality Disorder: Attention-Deficit/Hyperactivity Disorder and Conduct Disorder. European Archives of Psychiatry and Clinical Neuroscience, 251, 42-47. http://dx.doi.org/10.1007/s004060170067

[5] Fischer, M., Barkley, R.A., Smallish, L. and Fletcher, K. (2002) Young Adult Follow-Up of Hyperactive Children: Self-Reported Psychiatric Disorders, Comorbidity, and the Role of Childhood Conduct Problems and Teen CD. Journal of Abnormal Child Psychology, 30, 463-465. http://dx.doi.org/10.1023/A:1019864813776

[6] Davids, E. and Gastpar, M. (2003) Aufmerksamkeitsdefizit-/Hyperaktivitätsstörung und Substanzmittelabhängigkeit. Psychiatrische Praxis, 30, 182-186. http://dx.doi.org/10.1055/s-2003-39496

[7] Geurts, H.M., Verte, S., Oosterlaan, J., Roeyers, H. and Sergeant, J.A. (2005) ADHD Subtypes: Do They Differ in Their Executive Functioning Profile? Archives of Clinical Neuropsychology, 20, 457-477. http://dx.doi.org/10.1016/j.acn.2004.11.001

[8] Lijffijt, M., Kenemans, J.L., Verbaten, M.N. and van Engeland, H. (2005) A Meta-Analytic Review of Stopping Performance in Attention-Deficit/Hyperactivity Disorder: Deficient Inhibitory Motor Control? Journal of Abnormal Psychology, 114, 216-222.

[9] Solanto, M.V. (2001) Attention-Deficit/Hyperactivity Disorder: Clinical Features. In: Solanto, M.N., Arnsten, A.F.T. and Castellanos, F.X., Eds., Stimulant Drugs and ADHD, Oxford University Press, New York, 3-30.

[10] Escobar, R., Soutullo, C.A., Hervas, A., Gastaminza, X., Polavieja, P. and Gilaberte, I. (2005) Worse Quality of Life for Children with Newly Diagnosed Attention-Deficit/Hyperactivity Disorder, Compared with Asthmatic and Healthy Children. Pediatrics, 116, e364-e369. http://dx.doi.org/10.1542/peds.2005-0386 
[11] Barkley, R.A. (2002) Psycological Treatment for ADHD. Journal of Clinical Psychology, 63, 30-42.

[12] HardmAn, M.M., Drew, K.J. and Agen, V., BITA (2008) Psychology and Education of Exceptional Children (Community, School and Family). Translated by Alizadeh, H., Ganji, K., Yousefi, M. and Loyaandsouvenirs, F., 7th Edition, Danzhh Press.

[13] Bitter, J.R. (2004) Adlerian Group Counseling and Therapy Step-by-Step. New York and Hove.

[14] Sohrabi, M. (1999) Child and Adolcent Clinical Psychology. Tehran University, Tehran.

[15] Mash, E. and Barkly, R.A. (2003) Child Psychology. The Guilford Press, New York.

[16] Alizadeh, H. and Anderies, C. (2002) Interaction of Parenting Styles \& Attention Deficit Hyperactivity Disorder in Iranian Parents. Child \& Family Behavior Therapy, 24, 37-52. http://dx.doi.org/10.1300/J019v24n03 03

[17] Alizadeh, H., Applequilt, K.F. and Coolidge, F. (2007) Parental Self-Confidence, Parenting Styles and Corporal Punishment in Families of ADHD Children in Iran. Child Abuse \& Neglect, 31, 567-572. http://dx.doi.org/10.1016/i.chiabu.2006.12.005

[18] Biederman, J. and Faraone, S.V. (2005) Attention-Deficit Hyperactivity Disorder. Lancet, 366, 237-248. http://dx.doi.org/10.1016/S0140-6736(05)66915-2

[19] Anderies, A.H. (2001-2002) Parenting Styles in Families of Children with ADHD: A Cross-Cultural Study in Belgium and Iran. Vrije universiteit Brussel, Faculty of Psychology and Educational Science, Brussels. 